\title{
Effects of social class, sex, and region of residence on age at death from cystic fibrosis
}

\author{
John R Britton
}

\begin{abstract}
To determine the time trend in age at death from cystic fibrosis and the independent effects of social class, sex, and region of residence mortality data for England and Wales from 1959 to 1986 were analysed. Median age at death increased from 6 months in 1959 to 17 years in 1986 and was higher in most years from 1970 in male patients (by one to six years) and in social classes with non-manual occupations (by one to 12 years). Independent odds ratios for death above the median age for the year of death (calculated for years from 1974, when regions of residence were coded by regional health authority area) were $1.47(95 \%$ confidence interval 1.16 to 1.87 ) in male compared with female patients and $2 \cdot 75(2 \cdot 16$ to 3.52 ) in non-manual compared with manual social classes. The independent odds of death at above the median age also varied significantly among regions of residence by a ratio of up to $2 \cdot 67$.

Social class, sex, and region of residence are all potential determinants of survival of patients with cystic fibrosis. Social class is particularly likely to confound the effect of management in specialist centres on survival.
\end{abstract}

\section{Introduction}

Thirty years ago most patients with cystic fibrosis were expected to die in infancy or childhood. ${ }^{12}$ Now most can expect to survive into adulthood. ${ }^{3-13}$ This dramatic change, attributed to developments in diagnosis and management of cystic fibrosis, ${ }^{14}$ has been particularly noticeable among patients attending centres specialising in caring for those with cystic fibrosis. ${ }^{7.12} 15-17$ Consequently, many doctors support the expansion of the role of specialist centres. ${ }^{79}$ 15

Concentration of resources into specialist centres may be one means of providing the skill and support required in managing cystic fibrosis, but a disadvantage is that the clinics tend to be less accessible than more localised forms of health care. As a result the patients who attend specialist clinics may tend to be fairly affluent or more motivated to comply with treatment. One recent description of the characteristics of patients attending such a clinic in England clearly showed a social class bias, with $56 \%$ of patients coming from social classes I and II against an expected proportion of $20 \% .^{18}$ If social class is related to survival with cystic fibrosis then part of the apparently better performance of specialist clinics may be due to confounding by social class. The effect of social class has not, however, been controlled in comparisons of survival between clinic populations, and the extent of the effect of social class on survival with cystic fibrosis is not known.

The present study used data on mortality from cystic

fibrosis in England and Wales to establish whether social class is an independent determinant of age at death from cystic fibrosis and therefore a potential confounder of the effect of management in specialist clinics on survival. The study also documented time trends in age at death in England and Wales after 1959 and estimated the independent effects of patients' sex and the regional health authority in which they lived.

\section{Methods}

Mortality data for cystic fibrosis were obtained for England and Wales for 1959 to 1986 from the Office of Population Censuses and Surveys. Underlying cause of death, age at death, and sex had been coded throughout this period; social class from 1970; and regional health authority of usual residence from 1974 .

Underlying cause of death was coded by the International Classification of Diseases (ICD) category applying to cystic fibrosis. From 1959 to 1967 this was category 587.2, which also included other diseases of the pancreas. ${ }^{19}$ In 1968 the diseases of the pancreas were assigned to category 577.9 and a code exclusive to cystic fibrosis was created, being 273.0 between 1968 and 1978 and 277.0 thereafter. ${ }^{2021}$ The distribution of ages at death from cystic fibrosis and from other diseases of the pancreas in categories 273.0 and 577.9 for the three years after the change in coding showed a clear age distinction between the categories, with only one death from cystic fibrosis occurring above and five deaths not from cystic fibrosis occurring below the age of 50. ${ }^{22-24}$ Deaths recorded before 1968 were therefore adjusted for the inclusion of deaths from other pancreatic diseases coded in the same ICD category by excluding deaths at or over age 50.

Age at death for people surviving beyond their first birthday was coded as age in years at the last birthday, and for those dying before 1 year in days for the first week, weeks for the first month, and months thereafter. Social class of those who died aged $<16$ was coded by the mother's occupation or, if the mother had no paid occupation, that of the father; for those who died aged $\geqslant 16$ it was coded by their own occupation or that of the spouse. People in the armed forces were coded separately by codes that did not distinguish manual from non-manual occupations.

Data were entered into and analysed on mainframe computers at Nottingham University. Descriptive statistics were produced with the statistical package for the social sciences (SPSS X $)^{25}$ and logistic analyses with generalised linear interactive modelling (GLIM) ${ }^{26}$ Social class was classified into non-manual and manual categories in all analyses. As the distributions of ages at death were not normal in any year and no single transformation achieved normality the data were described in terms of median age at death by year, sex, and social class. The independent effects of sex, social class, and region of residence on the odds of death at City Hospital, Nottingham NG5 1PB

John R Britton, $\mathrm{MD}$, lecturer 
above the median age for the year of death were analysed in a multiple logistic regression analysis of the deaths that occurred after the introduction of the new regional health authority areas in 1974 with male sex, non-manual social class, and residence in the Northern Regional Health Authority as the reference point.

The median and 25 th centile of the distribution of age at death were estimated for birth cohorts from 1959 from published numbers of live births in England and Wales by year, ${ }^{2728}$ with the assumptions that one in 2500 liveborn infants would have cystic fibrosis, ${ }^{24}$ that cystic fibrosis would be registered as the underlying cause of death in all of these cases, and that no deaths from other causes were misclassified in the registrations of death from cystic fibrosis.

\section{Results}

After the effect of including deaths from causes other than cystic fibrosis in ICD category 587.2 from 1959 to 1967 had been allowed for 4107 people (2069 boys or men and 2038 girls or women) in England and Wales were estimated to have died from cystic fibrosis from 1959 to 1986 . The total number of deaths each year declined over the period (table I) and ranged from an estimated maximum of 185 in 1963 to a minimum of 94 in 1982. The distribution of age at death from cystic fibrosis changed with time, deaths before 1 year of age derreasing from 106 in 1959 to four in 1986. Median age at death increased from 6 months in 1959 to 17 years in 1986 (fig 1), and the range of age at death between the 25 th and 75 th centiles increased from 2 to 14 years. Median age at death was similar in the sexes until the 1970s but thereafter was higher in male patients in most years by one to six years (fig 2). From 1970 median age at death was higher in non-manual social classes than in manual classes in most years (fig 3 ) by one to 12 years.

After the introduction of coding of region of residence by regional health authority area in 1974 there were 1734 deaths from cystic fibrosis, for 160 of which no information on social class was known; a

TABLE I - Number of deaths by age and International Classification of Diseases (ICD) category 1959-86

\begin{tabular}{|c|c|c|c|c|c|c|c|c|c|c|c|c|c|c|}
\hline & \multicolumn{12}{|c|}{ Age (years) } & \multirow[b]{2}{*}{ Total } & \multirow{2}{*}{$\begin{array}{l}\text { Adjustec } \\
\text { total }^{\star}\end{array}$} \\
\hline & $<1$ & $1-$ & $5-$ & $10-$ & $15-$ & $20-$ & $25-$ & $30-$ & $35-$ & $40-$ & $45-$ & $\geqslant 50$ & & \\
\hline \multicolumn{15}{|c|}{$I C D$ category 587.2} \\
\hline 1959 & 106 & 44 & 18 & 4 & 2 & & & & 2 & & 2 & 17 & 195 & 178 \\
\hline 1960 & 122 & 30 & 19 & 7 & 2 & & & & 2 & & 3 & 28 & 213 & 185 \\
\hline 1961 & 97 & 30 & 10 & 8 & 2 & 1 & & & 1 & & & 18 & 167 & 149 \\
\hline 1962 & 107 & 35 & 19 & 7 & 2 & 2 & & & & & 1 & 24 & 197 & 173 \\
\hline 1963 & 102 & 50 & 19 & 9 & 1 & & & & & & 1 & 15 & 197 & 185 \\
\hline 1964 & 86 & 40 & 22 & 13 & 4 & 1 & 2 & & 1 & & & 16 & 185 & 170 \\
\hline 1965 & 73 & 31 & 20 & 10 & 8 & 2 & 2 & & 1 & & 1 & 13 & 161 & 148 \\
\hline 1966 & 78 & 34 & 27 & 14 & 6 & 3 & 1 & & & & 1 & 24 & 188 & 165 \\
\hline 1967 & 63 & 28 & 28 & 15 & 8 & 3 & & & 1 & & & 11 & 157 & 147 \\
\hline \multicolumn{15}{|c|}{ ICD category 273.0} \\
\hline 1968 & 74 & 31 & 31 & 11 & 11 & & 1 & & & & & & 159 & \\
\hline 1969 & 46 & 29 & 31 & 22 & 7 & 3 & 1 & & & & & & 139 & \\
\hline 1970 & 50 & 29 & 31 & 22 & 6 & 2 & I & & & & & 1 & 142 & \\
\hline 1971 & 58 & 24 & 31 & 18 & 10 & 2 & 2 & 1 & & & & 3 & 149 & \\
\hline 1972 & 41 & 27 & 38 & 20 & 9 & 3 & 1 & 1 & & & & 4 & 144 & \\
\hline 1973 & 40 & 14 & 32 & 29 & 11 & 7 & 3 & 1 & & & & 3 & 140 & \\
\hline 1974 & 29 & 21 & 33 & 27 & 8 & 7 & 4 & & & & 1 & & 130 & \\
\hline 1975 & 24 & 19 & 35 & 33 & 19 & 10 & 2 & & & & & 2 & 144 & \\
\hline 1976 & 23 & 17 & 34 & 34 & 20 & 5 & 12 & & & & & & 145 & \\
\hline 1977 & 24 & 13 & 26 & 26 & 22 & 12 & 4 & 1 & & & & & 128 & \\
\hline \multicolumn{15}{|c|}{ ICD category 277.0} \\
\hline 1978 & 20 & 14 & 22 & 40 & 25 & 12 & 5 & & & & & 1 & 139 & \\
\hline 1979 & 21 & 20 & 36 & 29 & 30 & 15 & 3 & 1 & 2 & & & 4 & 161 & \\
\hline 1980 & 10 & 9 & 28 & 33 & 32 & 14 & 7 & 1 & & & & 1 & 135 & \\
\hline 1981 & 12 & 11 & 23 & 38 & 23 & 20 & 5 & 1 & & & & 3 & 136 & \\
\hline 1982 & 10 & 8 & 20 & 20 & 11 & 18 & 6 & & & & & 1 & 94 & \\
\hline 1983 & 10 & 12 & 24 & 35 & 35 & 19 & 9 & 3 & & & & & 147 & \\
\hline 1984 & 7 & 6 & 12 & 28 & 22 & 27 & 9 & 3 & 3 & & & 2 & 119 & \\
\hline 1985 & 12 & 10 & 11 & 32 & 41 & 17 & 11 & & 2 & & 1 & 2 & 139 & \\
\hline 1986 & 4 & 7 & 21 & 16 & 25 & 23 & 14 & & 1 & & 2 & & 113 & \\
\hline
\end{tabular}

$\star$ Excluding deaths of people aged $\geqslant 50$.

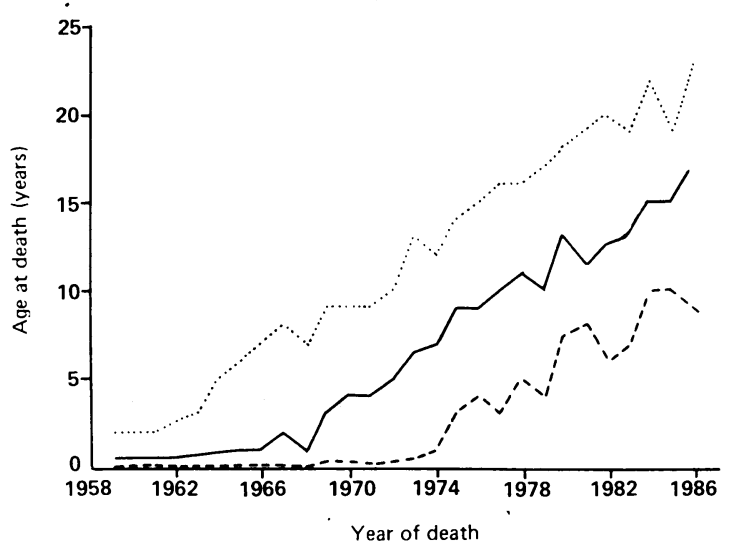

FIG 1-Ages at death from cystic fibrosis in England and Wales 1959-86. ---- $=25$ th Centile, $-=$ median, $\ldots . .=75$ th centile

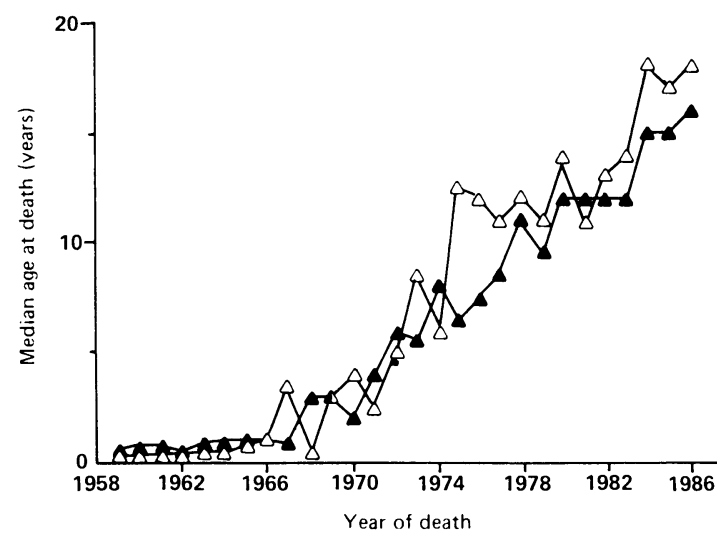

FIG 2-Median age at death from cystic fibrosis by sex in England and Wales 1959-86. $\triangle=$ Boys and men, $\boldsymbol{\Delta}=$ girls and women

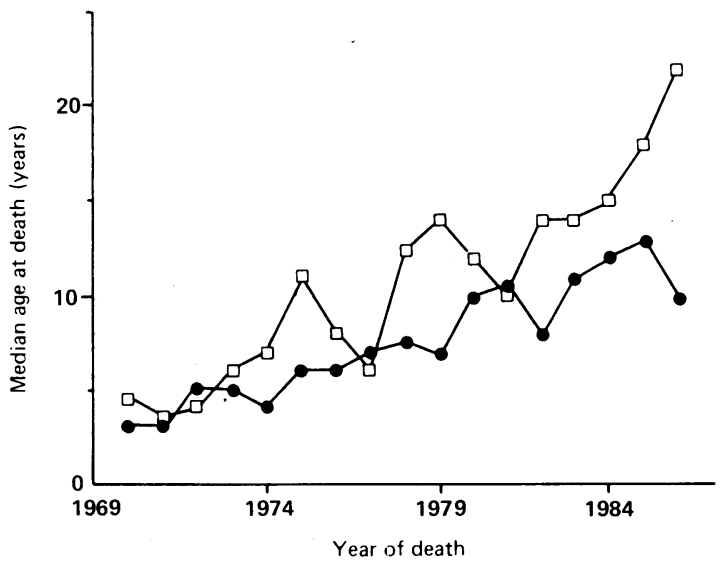

FIG 3-Median age at death from cystic fibrosis by social class in England and Wales 1970-86. $\square=$ Non-manual occupations, = manual occupations

further 290 subjects were coded as having no paid occupation and 20 as being in the armed forces; six had no area code. Thus there were complete data for 1258 deaths ( 605 boys or men and 653 girls or women). Occupation was coded as non-manual for 463 and manual for 763 . For deaths coded by the occupation of the father or spouse the $25 \mathrm{th}, 50 \mathrm{th}$, and 75 th centiles of the distribution of ages at death in pooled data for 1974 to 1986 were all higher in non-manual than in manual categories (table II). For deaths coded by own class the 75 th centile was higher for manual occupations. All 15 deaths coded by the occupation of the mother were in the non-manual category.

Independent odds ratios for death at age above the median for the year of death were 1.47 ( $95 \%$ confidence interval 1.16 to $1.87, \mathrm{p}<0.005)$ for male compared with female patients and $2 \cdot 75(2 \cdot 16$ to $3 \cdot 52, \mathrm{p}<0 \cdot 0001)$ for non-manual compared with manual social class. 
After the effects of sex and social class had been allowed for there were significant differences $(p<0 \cdot 005)$ in the odds of death at above the median age for the year among the areas of England and Wales, the maximum difference being a ratio of 2.67 between the Northern region and Wales (table III).

Estimated median survival based on estimates of the numbers of children affected by cystic fibrosis born each year increased from five years for the 1959 cohort to 15 years for children born in 1971. From 1972 less

TABLE II-Number of deaths among people with cystic fibrosis and 25th, 50th, and 75th centiles of distribution of ages at death in non-manual and manual social classes. Data are for 1974-86

\begin{tabular}{|c|c|c|c|c|c|}
\hline & \multirow[b]{2}{*}{ Social class } & \multirow{2}{*}{$\begin{array}{l}\text { No of } \\
\text { deaths }\end{array}$} & \multicolumn{3}{|c|}{ Age at death (years) } \\
\hline & & & 25th Centile & 50th Centile & 75th Centile \\
\hline \multicolumn{6}{|l|}{ No who died aged < $<16$ : } \\
\hline Coded by father's occupation & $\left\{\begin{array}{l}\text { Non-manual } \\
\text { Manual }\end{array}\right.$ & $\begin{array}{l}327 \\
682\end{array}$ & $\begin{array}{l}4 \\
3\end{array}$ & $\begin{array}{l}9 \\
7\end{array}$ & $\begin{array}{l}12 \\
11\end{array}$ \\
\hline Coded by mother's occupation & $\left\{\begin{array}{l}\text { Non-manual } \\
\text { Manual }\end{array}\right.$ & $\begin{array}{r}15 \\
0\end{array}$ & 15 & 15 & 15 \\
\hline \multicolumn{6}{|l|}{ No who died aged $\geqslant 16$ : } \\
\hline Coded by own occupation & $\left\{\begin{array}{l}\text { Non-manual } \\
\text { Manual }\end{array}\right.$ & $\begin{array}{r}138 \\
64\end{array}$ & $\begin{array}{l}20 \\
19\end{array}$ & $\begin{array}{l}22 \\
22\end{array}$ & $\begin{array}{l}25 \\
28\end{array}$ \\
\hline Coded by spouse's occupation & $\left\{\begin{array}{l}\text { Non-manual } \\
\text { Manual }\end{array}\right.$ & $\begin{array}{l}16 \\
16\end{array}$ & $\begin{array}{l}24 \\
20\end{array}$ & $\begin{array}{l}26 \\
25 \cdot 5\end{array}$ & $\begin{array}{l}43 \\
35\end{array}$ \\
\hline
\end{tabular}

TABLE III-Odds of death from cystic fibrosis in England and Wales at above median age in any year 1974-86

\begin{tabular}{|c|c|c|c|c|c|}
\hline & Estimate & Standard error & Odds ratio & $x^{:}$ & df \\
\hline \multicolumn{6}{|c|}{$\begin{array}{l}\text { Intercept (male sex, non-manual social class, residence in } \\
\text { Northern Regional Health Authority) }\end{array}$} \\
\hline Female sex & -0.39 & $0 \cdot 12$ & $0 \cdot 68$ & $9 \cdot 9$ & 1 \\
\hline Manual social class & $-1 \cdot 01$ & $0 \cdot 12$ & $0 \cdot 36$ & $67 \cdot 2$ & 1 \\
\hline Region of residence & & & & $34 \cdot 8$ & 14 \\
\hline South East Thames & $-0 \cdot 13$ & $0 \cdot 30$ & $0 \cdot 88$ & & \\
\hline North East Thames & -0.20 & $0 \cdot 29$ & 0.82 & & \\
\hline South Western & -0.21 & 0.33 & $0 \cdot 81$ & & \\
\hline South West Thames & -0.37 & $0 \cdot 36$ & $0 \cdot 69$ & & \\
\hline East Anglian & -0.39 & $0 \cdot 39$ & 0.67 & & \\
\hline Wessex & $-0 \cdot 40$ & $0 \cdot 34$ & 0.67 & & \\
\hline West Midlands & -0.69 & $0 \cdot 29$ & $0 \cdot 50$ & & \\
\hline Mersey & -0.89 & $0 \cdot 34$ & $0 \cdot 41$ & & \\
\hline Oxford & -0.91 & $0 \cdot 36$ & $0 \cdot 40$ & & \\
\hline Yorkshire & -0.92 & $0 \cdot 32$ & $0 \cdot 40$ & & \\
\hline North Western & -0.93 & $0 \cdot 30$ & $0 \cdot 39$ & & \\
\hline Trent & -0.93 & $0 \cdot 31$ & 0.39 & & \\
\hline North West Thames & -0.96 & $0 \cdot 32$ & $0 \cdot 38$ & & \\
\hline Wales & -0.98 & $0 \cdot 34$ & $0 \cdot 38$ & & \\
\hline
\end{tabular}

TABLE IV-Estimated number of births of infants with cystic fibrosis each year in England and Wales, number (percentage) of deaths from cystic fibrosis in each birth cohort, and estimated 25th and 50th centiles of ages at death by year of birth 1959-85

\begin{tabular}{|c|c|c|c|c|}
\hline \multirow[b]{2}{*}{ Year } & \multirow{2}{*}{$\begin{array}{l}\text { Estimated No of } \\
\text { births affected by } \\
\text { cystic fibrosis }\end{array}$} & \multirow{2}{*}{$\begin{array}{l}\text { No of deaths in } \\
\text { cohort with } \\
\text { cystic fibrosis (\%) }\end{array}$} & \multicolumn{2}{|c|}{ Estimated age at death (years) } \\
\hline & & & 25th Centile & 50th Centile \\
\hline 1959 & 300 & $216(72)$ & $0 \cdot 4$ & $5 \cdot 0$ \\
\hline 1960 & 314 & $260(82)$ & $0 \cdot 3$ & $4 \cdot 0$ \\
\hline 1961 & 325 & $256(79)$ & $0 \cdot 6$ & $8 \cdot 0$ \\
\hline 1962 & 336 & $266(79)$ & $0 \cdot 4$ & $7 \cdot 0$ \\
\hline 1963 & 342 & $244(71)$ & $0 \cdot 5$ & $9 \cdot 0$ \\
\hline 1964 & 351 & $242(69)$ & $1 \cdot 0$ & $12 \cdot 0$ \\
\hline 1965 & 346 & $195(56)$ & $2 \cdot 0$ & $16 \cdot 0$ \\
\hline 1966 & 340 & $200(59)$ & $1 \cdot 0$ & $14 \cdot 0$ \\
\hline 1967 & 333 & $184(55)$ & $3 \cdot 0$ & $17 \cdot 0$ \\
\hline 1968 & 328 & $203(62)$ & $1 \cdot 0$ & $13 \cdot 0$ \\
\hline 1969 & 320 & $141(44)$ & $6 \cdot 0$ & $>17 \cdot 0$ \\
\hline 1970 & 314 & $136(43)$ & $5 \cdot 0$ & $>16.0$ \\
\hline 1971 & 314 & $157(50)$ & $5 \cdot 0$ & $15 \cdot 0$ \\
\hline 1972 & 290 & $127(44)$ & $6 \cdot 0$ & \\
\hline 1973 & 271 & $91(34)$ & $8 \cdot 0$ & \\
\hline 1974 & 256 & $83(32)$ & $8 \cdot 0$ & \\
\hline 1975 & 242 & $75(31)$ & $7 \cdot 0$ & \\
\hline 1976 & 234 & $59(25)$ & $10 \cdot 0$ & \\
\hline 1977 & 228 & $56(25)$ & & \\
\hline 1978 & 238 & $43(18)$ & & \\
\hline 1979 & 255 & $41(16)$ & & \\
\hline 1980 & 262 & $21 \quad 8)$ & & \\
\hline 1981 & 254 & $27(11)$ & & \\
\hline 1982 & 250 & $18(7)$ & & \\
\hline 1983 & 252 & $15(6)$ & & \\
\hline 1984 & 255 & $10(4)$ & & \\
\hline 1985 & 262 & 12 (5) & & \\
\hline
\end{tabular}

*One birth in 2500 . than half of the estimated birth cohort for each year died from cystic fibrosis. The estimated 25 th centile of the age at death in these cohorts increased from 5 months in 1959 to 10 years in 1976 (table IV).

\section{Discussion}

This study was conducted primarily to determine whether the effect of social class is likely to confound differences in survival between patients with cystic fibrosis cared for in a specialist clinic and those receiving care locally. Mortality data from the Office of Population Censuses and Surveys were chosen as they are the only population based data available for cystic fibrosis in England and Wales that include details of social class. Data on social class were available for a high proportion of deaths after coding began in 1970; an occupation code was present for $86 \%$ and non-manual or manual occupation could be identified for over $70 \%$.

As cystic fibrosis was coded with other diseases of the pancreas before 1968 the numbers of deaths from cystic fibrosis each year from 1959 to 1967 were estimated by excluding deaths at age 50 or over. In the three years immediately after the segregation of deaths from cystic fibrosis into an exclusive code in 1968 the proportion of deaths misclassified by this process would have been less than $2 \%$ of the total; thus it is unlikely that the estimates of numbers and median age at death before 1968 were seriously distorted.

The extent to which the data comprise a complete record of mortality from cystic fibrosis is determined by the degree of misclassification, under-reporting and underdiagnosis of the disease. Misclassification of reported deaths from cystic fibrosis into other disease categories is unlikely to have been a major influence, ${ }^{16}$ but the degree of misclassification of deaths from other causes into the category for cystic fibrosis or of under-reporting or underdiagnosis of cystic fibrosis is less clearly established. In the present study the discrepancy between the expected number of children born with cystic fibrosis each year from 1959 to 1962 and the observed number of deaths from cystic fibrosis in the birth cohorts registered by the end of 1986 was about $20 \%$, suggesting that unless these people are still alive, contrary to estimates of life expectancy at the time of birth, ${ }^{12}$ up to $20 \%$ in the early cohorts may have died with unrecognised or unreported disease.

The data were analysed by median age at death so that all information on social class of people who died after 1970 could be used. The alternative approach would be to use birth cohort analysis; the disadvantages of this method in the present study are that the analysis would be restricted to mortality at relatively early ages in the small numbers of deaths in people born after 1970; inclusion of the effects of region of residence would further restrict the analysis to those born after 1974; differences in existing methods of collecting data would mean that data for deaths and for the population at risk would not be reliably linked for social class; and cohort analysis requires an unsubstantiated assumption that the incidence of cystic fibrosis is the same in all social classes. A shortcoming of the approach used, however, was that the data did not include information on current survivors with cystic fibrosis, so that generalisation of the effects of social class, sex, and region of residence from the present study assumes that effects among those who died also apply to current and future survivors.

The most striking observation from the data is the increase in median age at death, from 6 months in 1959 to 17 years in 1986 (fig 1). The increase was apparently linear from the late 1960s. The estimates of survival in successive birth cohorts (table IV) show a similar trend, though these figures may be overestimates 
because of underdiagnosis and under-reporting of cystic fibrosis. Several factors are thought to account for the increasing life expectancy, including improvements in the management of meconium ileus, ${ }^{57113031}$ the introduction of effective antibiotics for staphylococcal and pseudomonal infections and of vitamin and pancreatic enzyme supplementation, ${ }^{1+}$ and the increased ascertainment of milder forms of cystic fibrosis in adults..$^{2322-36}$

Since the mid-1970s median age at death has tended to be higher in male patients and in patients with nonmanual occupations. The odds of death at above the median age for the year of death were independently related from 1974 to sex, social class, and region of residence. Some reports have noted significantly longer survival in male patients $s^{3615}$ and others have

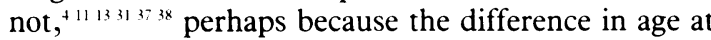
death (about two years in the present study) is fairly small. The reason for the male advantage is not clear, and confounding of increasing age at death with time makes it uncertain whether the increased survival in male patients is due to a differential effect of treatment or to more rapid deterioration in female patients after late childhood. ${ }^{39}$

After the effects of sex had been allowed for social class had a strong and independent effect on age at death. The effect of social class in the present study is open to bias by reverse causation (that is, cystic fibrosis determining social class) and by confounding by the method of coding social class. Reverse causation is particularly likely in adults, who represent a success in survival, and may because of respiratory disability tend to select non-manual occupations. This influence will be offset to some extent by the fact that adults in manual occupations are likely to be those with the least disability and the best prognosis. For deaths under age 16 coding of social class by the mother's occupation may be associated with prolonged survival as mothers may be unlikely to take paid work of any category unless their child is old enough and well enough to attend school. Father's social class is likely to be the least biased indicator of family lifestyle but is available in data from the Office of Population Censuses and Surveys only if death occurred below age 16 and in the absence of a working mother.

The social class of most $(83 \%)$ of those who died was coded by the father's or spouse's occupation; this showed a consistent trend towards a higher age at death in non-manual occupations (table II). In deaths coded for own occupation the age at death represented by the 75th centile was higher in the manual category, supporting the suggestion that adults who choose manual occupations tend to have a better prognosis. The small number of deaths with social class coded by the mother's occupation were all in the non-manual category, and age at death was higher than in groups coded by the father's occupation. This supports the association of working mothers with older children, and although the group was small, the fact that all of the mothers had non-manual occupations suggests that these older children tended to come from families of a higher social class. Thus despite the bias inherent in the methods of recording social class the consistent effect of social class suggests that the observed relation between higher social class and higher age at death is valid. The lower ages at death in the lower social classes may be caused either by a lack of resources to permit visits to hospitals or the local doctor or to provide medicines and dietary supplements, or by factors such as increased parental smoking, poor quality or overcrowded housing, and lower levels of education. ${ }^{+1}$

After the effects of sex and social class were allowed for there were appreciable differences in the odds of death at above median age among the regions of England and Wales. The differences had no clear geographical pattern. Climate, air pollution, the availability and nature of health services, and the differential effects of social class are all potential contributors to these differences.

This study showed that the prognosis of cystic fibrosis improved greatly in England and Wales over the past 30 years and that social class, sex, and region of residence were all independent determinants of age at death. Given the disproportion of non-manual occupations among patients attending at least one specialist clinic in England, ${ }^{18}$ social class is particularly likely to confound the association between attendance at specialist clinics and improved survival. The reasons for the effect of social class on survival with cystic fibrosis should be investigated further to determine whether alternative, possibly less centralised, forms of health care might be more effective for patients from lower social classes. Current plans to provide facilities to care for the growing numbers of patients with cystic fibrosis should take particular account of the effect of social class.

I thank Richard Somerville and Nirupha Lakhani from the Office of Population Censuses and Surveys for supplying the raw data, Antoni Wisniewski for help with entering data, Dr David Strachan for advice in preparing the paper, Professor Anne Tattersfield for comments on the manuscript, and the Medical Research Council for financial support.

1 Andersen DH. Cystic fibrosis of the pancreas. $\mathcal{F}$ Chronic Dis 1958;7:58-90.

2 Polgar G, Denton R. Cystic fibrosis in adults. Am Rev Respir Dis 1962;85: 319-27

3 Pogue RE, Warwick WJ. Cystic fibrosis. A new challenge to internal medicine. Minn Med 1969;52:1551-5.

4 Huang NN, Macri CN, Girone J, Sproul A. Survival of patients with crstic fibrosis. A $m$ J Dis Child 1970;120:289-95.

5 George L, Norman AP. Life tables for cystic fibrosis. Arch Dis Child $1971 ; 46: 139-43$.

6 Warwick WJ, Pogue RE, Gerber HU, Nesbitt CJ. Survival patterns in crstic fibrosis. I Chronic Dis 1975;28:609-22.

7 Dynesen H. Flensborg EW. Prognosen for cystisk fibrose i Danmark 1945-1974. Ugeskr L aeger 1978;140:463-70.

8 Phelan PD, Allan JL, Landau LI, Barnes GL. Improved survival of patients with cystic fibrosis. Med F A Ast 1979;1:261-3.

9 Warwick WJ. Prognosis for survival with cystic fibrosis: the effects of carly diagnosis and cystic fibrosis center care. Acta Paediatr Scand [Suppl] 1982;301:27-31.

10 Nielsen OH, Schiotz PO. Cystic fibrosis in Denmark in the period 1945-1981. Evaluation of centralised treatment. Acta Paediatr Scand [Suppl] 1982;301 107-19.

11 Hill DJS, Martin AJ, Davidson GP, Smith GS. Survival of erstic fibrosis patients in South Australia. Med f A ust 1985;143:230-2.

12 Geddes DM, Dodge JA. Improving prognosis for cystic fibrosis in the UK 1977-1985. Thorax 1988:43:838

13 Hudson I, Phelan PD. Are sex, age at diagnosis, or mode of presentation prognostic factors for crstic fibrosis? Pediatr Pulmonol 1987;3:288-97.

$1+$ W'ood RE, Boat TF, Doershuk CF. Crstic fibrosis. Am Rev Respir Dis 1976;113:833-78

15 Stern RC. Boat TF, Doershuk CF, Tucker AS, Primiano FP, Matthews LW. Course of cystic fibrosis in 95 patients. I Pediatr 1976;89:406-11.

16 Phelan P, Hey E. Cystic fibrosis mortality in England and Wales and in Victoria, Australia 1976-80. Arch Dis Child 1984;59:71-83.

17 Corey M, McLaughlin FJ, Williams M, Levison H. A comparison of survival growth and pulmonary function in patients with cystic fibrosis in Boston and Toronto. Fournal of Clinical Epidemiology 1988;41:583-91.

18 Penketh ARL, Wise A, Mearns MB, Hodson ME, Batten JC. Cystic fibrosis in adolescents and adults. Thorax 1987:42:526-32.

19 World Health Organisation. Manual of the intermational statistical classification of diseases, injuries and cause's of death. 7th Revision, 1955. (jeneva: WHO, 1957

20 World Health Organisation. Manual of the international statistical classification of diseases, injuries and causes of death. 8th Revision, 1965. (ieneva: WH(), 1967

21 W'orld Health Organisation. Manual of the international statistical classification of diseases, injuries and causes of death. 9th Revision, 1975. (ieneva: WHO, 1977

22 Office of Population Censuses and Surveys. Registrar General's statistical recien of England and Wales for the year 1968. Part I: tables, medical. London: HMSO, 1970

23 Office of Population Censuses and Surveys. Registrar General's statistical reviea of England and Wales for the year 1969. Part I: tables, medical. London: HMSO, 1971 .

24 Office of Population Censuses and Survers. Registrar General's statistical review of England and Wales for the vear 1970. Part I: tables, medical. London: HMSO, 1972

25 SPSS-X Inc. SPSS-X users guide. 2nd ed. New York: McGraw Hill, 1986.

26 Numerical Algorithms Group. Generalised linear interactive modelling system, release 3.77. Oxford: Royal Statistical Socicy. 1986

27 Office of Population Censuses and Survers. Birth statistics 1975. London: HMSO 1978. Seriensuses and

28 Office of Population Censuses and Surveys. Birth statistics 1985. London: HMSO 1986 Series FMI No 12

29 Allan JL, Robbic M, Phelan PD, Danks DM. The incidence and presentation of cystic fibrosis in Victoria 1955-1978. A ust Paediutr f 1980;16:270-3. 
30 McPartlin JF, Dickson JAS, Swain VAJ. Meconium ileus. Immediate and ong-term survival. Arch Dis Child 1972;47:207-10

31 Wilmott RW, Tyson SL, Dinwiddie R, Matthew DJ. Survival rates in cystic fibrosis. Arch Dis Child 1983;58:835-6.

32 Shwachman H, Dooley RR, Guilmette F, Patterson PR, Weil C, Leubner H. Cystic fibrosis of the pancreas with varying degrees of pancreatic insufficiency. A $m$ f Dis Child 1956;92:347-68.

33 Karlish AJ, Tarnoky AL. Mucoviscidosis as a factor in chronic lung disease in adults. Lancet 1960;ii:514-5.

4 Anderson EG, Laszlo G, Brown HM. A case of mucoviscidosis in an adult. $B r f$ Dis Chest 1965;59:173-6.

35 Gracey M. Anderson CM. Cystic fibrosis of the pancreas in adolescence and adulthood. Australian Annals of Medicine 1969;18:91-101.
36 Tomashefski JF, Christoforidis AJ, Abdullah AK. Cystic fibrosis in young dults, Chest 1970:57:28-36.

37 Knoke JD, Stern RC, Doershuk CF, Boat TF, Matthews LW. Cystic fibrosis: the prognosis for five-year survival. Pediatr Res 1978;12:675-9.

38 Wilmott RW, Tyson SL, Matthew DJ. Cystic fibrosis survival rates. Am 7 Dis Child 1985;139:669-71.

39 Corey M, Levison H, Crozier D. Five- to seven-year course of pulmonary function in cystic fibrosis. Am Rev Kespir Dis 1976;114:1085-92.

40 Black D, Morris JN, Smith C, Townsend P. The Black report. In: Townsen $\mathrm{P}$, Davidson $\mathrm{N}$, eds. Inequalities in health. Harmondsworth: Penguin, 1982:39-233.

(Accepted 2 December 1988)

\title{
Plasma lipid and coagulation factor concentrations in insulin dependent diabetics with microalbuminuria
}

\author{
S L Jones, C F Close, M B Mattock, R J Jarrett, H Keen, G C Viberti
}

\section{Abstract}

Objective-To determine whether insulin dependent diabetics with microalbuminuria have significant abnormalities in concentrations of lipoproteins, apolipoproteins AI and B, fibrinogen, and clotting factor VII which could result in increased cardiovascular risk.

Design-Case-control study.

Setting-Outpatient department of a metabolic ward.

Patients-Group of 20 insulin dependent diabetics with urinary albumin excretion rates greater than $30 \mu \mathrm{g} / \mathrm{min}$ (microalbuminuria) and 20 individually matched insulin dependent diabetics with normal urinary albumin excretion rates (below $30 \mathrm{\mu g} / \mathrm{min}$ ) matched for age, sex, and duration of diabetes.

Interventions-Fasting venous blood samples were taken for determination of concentrations of glucose, glycated haemoglobin, lipoproteins, apolipoproteins AI and B, fibrinogen, and factor VII. Height, weight, arterial pressure, and usual insulin dose were recorded, and each patient was given a dietary questionnaire to be completed at home.

End point-Comparison of blood pressure and concentrations of lipoproteins, apolipoproteins AI and $B$, and fibrinogen in the diabetics with microalbuminuria and the controls.

Measurements and main results-Patients with microalbuminuria had significantly higher concentrations of low density lipoprotein cholesterol (mean $3.33(\mathrm{SE} 0.20) v 2.84(0.12) \mathrm{mmol} / \mathrm{l})$ and very low density lipoprotein cholesterol $(0.30(0.05) v 0.17$ $(0.03) \mathrm{mmol} / \mathrm{l})$ than controls but significantly lower concentrations of high density lipoprotein 2 subfraction cholesterol $(0.32 \quad(0.04) \quad v \quad 0.54$ $(0.04) \mathrm{mmol} / \mathrm{l})$. Concentrations of total triglyceride $(1.11(0.14) \quad v \quad 0.68(0.08) \quad \mathrm{mmol} / \mathrm{l})$, very low density lipoprotein triglyceride $(0.56(0.10) v 0.30$ $(0.05) \mathrm{mmol} / \mathrm{l})$, apolipoprotein B $(0.88(0.06) v 0.67$ $(0.03) \mathrm{g} / \mathrm{l})$ and fibrinogen $(2.2(0 \cdot 1) v 1.9(0 \cdot 1) \mathrm{g} / \mathrm{l})$, and diastolic arterial pressure (80 (2) $v 74$ (2) $\mathrm{mm} \mathrm{Hg}$ ), were also higher in patients with microalbuminuria.

Conclusions-Cardiovascular risk factorsnamely, disturbances in lipoprotein and apolipoprotein concentrations, increased fibrinogen concentration, and increased arterial pressure - are already present in insulin dependent diabetics with microalbuminuria. The increased risk of coronary heart disease in patients with clinical proteinuria may result from prolonged exposure to these risk factors, which are present before any impairment of renal function.

\section{Introduction}

Insulin dependent diabetics who develop clinical proteinuria have a much greater risk of premature death from cardiovascular complications than those without proteinuria. ${ }^{12}$ A subclinical increase in urinary excretion of albumin (microalbuminuria) predicts the development of persistent clinical proteinuria and renal failure in insulin dependent diabetics. ${ }^{3-6}$ In both prospective and cross sectional studies of non-insulin dependent diabetics microalbuminuria strongly indicated an increased risk of death from cardiovascular complications ${ }^{7-9}$ and it may also do so in nondiabetics. ${ }^{111}$

At the stage of clinical proteinuria and progressive renal failure changes in plasma lipoprotein concentrations, ${ }^{12-14}$ an increase in systemic blood pressure, ${ }^{12}$ and haemorrheological changes ${ }^{1516}$ have each been proposed as contributing to the increased cardiovascular risk. The situation is less clear in patients with microalbuminuria, in whom renal function is normal or even supranormal. Several workers have shown a raised arterial blood pressure at this stage,${ }^{4617}$ and control of blood glucose concentration has also been reported to be worse. ${ }^{17}$ Reports have suggested that profiles of lipoprotein concentrations are changed in diabetics with microalbuminuria and lie between those in diabetics with normal albuminuria and diabetics with clinical proteinuria. ${ }^{1314}$ The differences, however, were not significant and could have been accounted for by the poorer glycaemic control in the diabetics with microalbuminuria.

In this case-control study we compared concentrations of lipoproteins, apolipoproteins, fibrinogen, and factor VII in insulin dependent diabetics with microalbuminuria and diabetics with normal albumin excretion rates with similar control of their blood glucose concentration.

\section{Patients and methods}

Twenty insulin dependent diabetics with microalbuminuria were matched individually for age, sex, and duration of diabetes with 20 insulin dependent diabetics shown to have normal rates of albumin excretion. All were less than 65 years old and had had diabetes since before the age of 35 . All patients were Europids and received the standard dietary advice given to diabetics. None were taking drugs other than insulin apart from two patients with microalbuminuria, who were receiving long term thyroxine and cortisol replacement treatment. No patient had a history of renal disease or of drug or alcohol abuse.

As part of a collaborative screening programme ${ }^{18}$ we
Correspondence to:

$\operatorname{Br} \operatorname{Med} \mathcal{F}$ 1989;298:487-90 